\title{
The Pharmakon of Educational Technology: The Disruptive Power of Attention in Education
}

\author{
David Lewin ${ }^{1}$
}

Published online: 29 February 2016

(C) The Author(s) 2016. This article is published with open access at Springerlink.com

\begin{abstract}
Is physical presence an essential aspect of a rich educational experience? Can forms of virtual encounter achieve engaged and sustained education? Technophiles and technophobes might agree that authentic personal engagement is educationally normative. They are more likely to disagree on how authentic engagement is best achieved. This article argues that educational thinking around digital pedagogy unhelpfully reinforces this polarising debate by failing to recognise that digitalisation is, as Stiegler has argued, pharmacological: both a poison and a cure. I suggest that Biesta's critique of learnification can be applied to online learning, but that any such application does not sufficiently acknowledge the pharmacological nature of modern technology. While Stiegler has something important to contribute on the relation between technology, attention and education, I suggest his account is rather too bound up with critical theories of technology. In the end I turn to philosophers of religion, such as Eliade and Smith to suggest different ways of conceiving the role of attention in education that does set technologies up over/ against the formation of attention essential to education.
\end{abstract}

Keywords Biesta $\cdot$ Stiegler $\cdot$ Eliade $\cdot$ Attention $\cdot$ Technology

Is physical presence an essential aspect of a rich educational experience? Can forms of virtual encounter achieve engaged and sustained education? Technophiles and technophobes might agree that authentic engagement is educationally normative. They are more likely to disagree on how authentic engagement is best achieved. Perhaps this disagreement assumes too straightforward a dichotomy between the virtual and the physical. It may be haunted by an artificial and romantic construction of 'technology' that fails to recognise the historical (and even ontological) continuities between pre-industrial and present day

David Lewin

david.lewin@strath.ac.uk

1 University of Strathclyde, Glasgow, UK 
technological developments. ${ }^{1}$ It seems that, like football teams, opposed sides of vanishing binaries draw unreflective allegiances: natural/artificial; virtual/physical; present/absent. But the banal rationalisation that all techne is ultimately a poiesis, all art or craft is a bringing-forth-an observation that in Heidegger's hands has ontological signification (Heidegger 1977) - should not distract us from the implications of the fact that we live as though the binaries were real.

In this paper I will argue that we should avoid naturalising technologies as essential or even neutral with regard to human development. I intend to complicate the simplistic dichotomy that places techno-optimists over/against techno-pessimists in order to explore the potential for a more 'humanised' form of online education: one that contributes positively to the becoming of human identity. Partly this will be about recognising the extent to which technology is not an appendage to human identity, but is intrinsic to it. Likewise educational technologies are not recent extensions to a fundamentally 'atechnical' process or essence, but have always formed and shaped the development of knowledge. It is important, therefore, to recognise that forms of specifically educational technology go at least as far back as the 14 th-century BCE. ${ }^{2}$ Perhaps language should be defined as the first technology, and the first educational technology. The development of writing through the use of various technologies - of clay tablets, paper, writing instruments, and writing itself-is a key moment in the history of education in the modern (post-Enlightenment) sense of the term. The significance of reading and writing is clear today through a focus on literacy, but as Jan Masschelein has shown, literate culture goes hand in hand with the development of pedagogy, and the technologies that support pedagogy (Masschelein 2011). In discussing Vilem Flusser, Joris Vlieghe has recently expressed the link between technologies of writing and our capacity for thinking thus:

It is only due to the technology of writing that thinking, or at least linear and diachronic thought, became possible in the first place: the clarity and orderliness of our thinking is dependent upon the coming into existence of a specific, material, and mechanical practice of jotting down letters and words (Vlieghe 2014, p. 524).

Is thinking really so linear? Are we so enframed by a linear concept of time that we are willing to concede the power of thought to this feature of our being? Does the linear conception of time not locate the discussion too narrowly within a Western 'Abrahamic' frame of reference? ${ }^{3}$ Still, Vlieghe may be right to suggest that the developments of literacy and technology and the construction of the modern self can scarcely be separated. This identification has particular resonance with the philosophy of Bernard Stiegler for whom the emergence of human nature and the development of technology are coeval. This is important because it deconstructs the romantic and prelapsarian view of human nature

\footnotetext{
1 The so-called 'classical' tradition within philosophy of technology (e.g. Heidegger, Ellul, Marcuse, Jonas) tended to assume a sharp division between ancient and modern technology which has more recently been challenged both by an empirical turn in philosophy of technology (Achterhuis 2001) as well as by the work of philosophers like Bernard Stiegler whose appropriation and innovation over the Heideggerian tradition will be discussed later on.

2 Archaeologists have evidence of the use of wax tablets from 14th-century BCE (Payton 1991; Friesen 2014).

3 A host of religious concepts that occur within the Abrahamic faiths reflect the concept of linear time, in contrast to 'Eastern traditions' which often have more cyclical conceptions of time: afterlife; eschatology; progress; destiny; hope; 'parousia'; these are all conceptions particular to Western theological views. I have argued elsewhere that the orientation to the future embedded in these traditions correlates with the development of technology that emerged, in a sustained fashion, in cultures of this linear time (Lewin 2013).
} 
unsullied by the instrumentalism of homo technicus. If human beings are not, in any meaningful sense prior to technology, then the tensions between technology and education are transformed, a point I shall develop later. ${ }^{4}$

Today we identify educational technology with the devices and affordances that provide educational institutions, teachers, and learners with enhanced opportunities to learn, or at least, with more convenient forms of learning. The growth in learning online is one obvious example here and seems to make the commitment to the physical habitat of education obsolete or anachronistic. Still many educators speak for the uncanny quality of physical presence; that being physically face-to-face with students has a singular, irreducible pedagogical power. This raises a question: is the interest in online education really pedagogical? It seems highly likely that the impetus to develop online education is founded, first and foremost, on economic rather than pedagogic concerns, since online learning is clearly driven by large corporations invested in the proliferation of online technologies, as well as affording extraordinary scalability and restricting the greatest cost in traditional education, the expense of the teachers. So my general orientation towards the optimistic rhetoric around online education is sceptical. The concerns about online education expressed here in no way justify a wholesale rejection of online life, something that for most of us today is unimaginable. Indeed, as Rupert Wegerif has argued, the digital age can enhance the experience of dialogue for pedagogy (Wegerif 2007). There are, no doubt, further intrinsic benefits to online education, such as giving confidence to some students who, for whatever reasons, find the face-to-face encounter too difficult, or by providing opportunities and giving voice to those who might otherwise be excluded from education because of social or practical restrictions. But where the resources of time and money are unrestricted, isn't the educational encounter best served in person? Of course, time and money are never unrestricted, and only disengaged speculations about some utopian future would seriously entertain such a scenario. And so perhaps we ought to accept that the prime interest of the online education industry is, and needs to be, the efficiencies that can be harnessed through the reconfiguring, if not full overcoming, of space and time. So despite a note of caution, I want to explore some of the ways in which technologies and virtual spaces occupy a grey area in educational theory and practice. The tensions outlined here are well illustrated by two recent online publications that play with techniques-or technologies - of language: the manifesto and the disputation.

The 'Manifesto for teaching online' has been developed alongside research into digital education at the University of Edinburgh (2011). Unsurprisingly for a manifesto, the statements made are pithy and provocative, opening with the rather overstated claim that "Distance is a positive principle, not a deficit" (Manifesto for Teaching Online 2011). As well as being a challenging statement of how to think differently about online education, the manifesto plays the role of contextual corrective, by drawing attention to how, for example, we tend to see spatial distance as a deficit and the physical encounter as normative in education. The manifesto is critical of commonplace approaches to online education that involve simply making learning materials available over the Internet. This commonplace approach can certainly be construed as an example of placing economics before pedagogy, while also taking that 'traditional' face-to-face to be educationally normative.

\footnotetext{
4 A similar deconstruction of Rousseau's opening gambit in The Social Contract "Man is born free and everywhere he is in chains" could be developed, though I will not do so here. Rousseau's binary between nature and culture is, of course, fundamental to his pedagogy.
} 
By contrast Alan Jacobs (2015) has created 79 Theses on Technology. For Disputation, a provocative and unsettling record of technological ambivalence, seeming to take a roughly opposed view to the manifesto in asserting the complexity and undecidability of technology. (In the following section entitled 'The Pharmakon of technics', I give a brief account of Derrida's use of undecidability as the inability to decide between certain dichotomies, and why it applies to technology). The kinds of reading and responding (through online comment) that digital literacy affords are truly exciting but also, suggests Jacobs, disappointing, since the opportunities to take online debate seriously is undermined by a humourless antagonism that characterizes much online debate and seems a long way from genuine dialogue.

But is it really fair for me to oppose this manifesto and disputation since both are devices rather than static positioning statements? While I regard the disputation to be more effective in breaking us out of our habitual ways of thinking about technology, both testify to a cultural drift towards online learning that is still rarely subject to serious debate. And here is the point: these provocations offer rare moments to engage in deliberation about the nature of technology within education, whereas too many statements about the proper place of technology present a simple statement for or against. I want to argue that this deliberation is not widespread because educators are either seduced by the affordances of online life, or wish to reject them as the work of the devil. I now move to a specific analysis of the language of learning as it reflects the move to learning online since here some of the concerns can be more concretely elaborated.

\section{Online Education or E-Learning}

Online education is a complex and multi-faceted phenomenon and can hardly be defined in straightforward terms. Sian Bayne has recently examined the range of terms used in this broad domain, "from 'ICT for learning' to 'educational technology', from 'computer based learning' to 'online education' each differently-inflected term has had its moments and its adherents" (Bayne 2015, p. 5) and shows how the phrase 'technology enhanced learning' has become dominant at least within UK educational discourse. It is worth considering here whether online education is equivalent to online learning or e-learning, terms which Wikipedia presents as synonymous. ${ }^{5}$ This is an important question for philosophers of education (and educationalists generally) because education as a substantive and multifaceted phenomenon can be distinguished from learning in important ways, as Gert Biesta has shown in his critical analysis of the "learnification of education" (Biesta 2010). For Biesta the shift in our language from education to learning is related to the fact that we have lost sight of the questions of educational purpose and values (Biesta 2010, p. 14). Theorists such as Norm Friesen and Sian Bayne have recognised how Biesta's critique of learnification might have particular relevance for technology-enhanced learning (Friesen 2013; Bayne 2015). Friesen has argued that with the rise of behaviourist and constructivist learning theories in the 20th century, a 'technologization' of teaching and learning practices brings about a situation where learning as a natural and "universally occurring process that can be best facilitated through instructional technique remains uncontested" (Friesen 2013, p. 32). In brief, Friesen argues that, "this vocabulary represents a particular technologization or instrumentalization of education, a process that makes educational practices and priorities appear germane to, or even incomplete without, technological

\footnotetext{
5 At the time of writing Wikipedia redirects 'Online Education' to 'E-Learning.'
} 
rationalization and reshaping" (Friesen 2013, p. 21). So how does the language of learning reflect this reshaping and technologization of education?

E-learning certainly has some of the characteristics that Biesta identifies with the shift towards the language of learning. E-learning is more consumer-driven in the sense that it tries more than ever before to adapt to the needs and contexts of learners. This can be observed in the spatio-temporal flexibility of online education: it can take place synchronously (in 'real time') or asynchronously (whenever suits the learner, i.e., self-paced), though the asynchronous component is more characteristic of learning online where learners engage in email, blogs, forums, wikis, audio, video etc. This flexibility can facilitate independence of mind and self-directed attitudes towards education but more negatively, plays into the 'student-as-consumer' attitude. E-learning also tends to be individualistic, often replacing classroom experiences with structured activities that can be tutor led but are typically self-directed, emphasising learning as a process about (and only about) the learner who acquires knowledge, understanding, or skills. Despite his critical analysis of the shift to a culture of learning, Biesta also acknowledges that these features of learning (and by implication e-learning) have some emancipatory potential. The shift reflects deeper historical currents that see a less centralised and less authoritarian view of education in which the student is understood as co-constructor of their own understanding of the world. However, Biesta argues that the language of 'learning' does not just reflect a more democratic or inclusive form of pedagogy in which the learner is placed centre-stage. On the contrary, the learnification culture is threatening to democratic and inclusive ways of being because it reduces democratic processes to the aggregation of individual desires (Biesta 2010). To service aggregated desires does not bring into question the ground and context of those desires. Moreover, the learning culture does not foster reflection upon the purposes of education, but rather takes for granted that purposes basically equate to what individuals want them to be: in other words they are regarded as preferences. Of course this is thoroughly individualistic but Biesta is hinting here at a more fundamental problem: that education properly understood, points to a shared cultural enterprise which is lost in the culture of learnification. This point is really calling for a radical reorientation of our hollowed out culture of learning since it reintroduces ontology into education: that education has an orientation to something real and that individual desires must, in some sense, be in dialogue with that reality: both informing it and being informed by it.

An important question emerges from this: what does education online do to the transformation of education into learning? Does it reinforce and extend the shift from education to learning, or does it limit and reorganise our relationship to the purposes of education? Are we at liberty to define our own purposes as consumers? For Biesta the notion that learner preferences should delineate the purposes of education is fundamentally flawed. It assumes that the learner is able to make independent and informed judgements about the good conferred by the educational experience. The fact that students are not in a position to choose their own education as though they are selecting a new washing machine distinguishes education as a profession from the marketplace (Biesta 2006, pp. 20-21). In the idealised market model the consumer knows what they want and will make a rational selection from the offerings available. While there are situations where the consumer needs to be educated by the producer, the market model is predicated on the ideal of the informed consumer. For Biesta what characterises the education profession, on the other hand, is the way it inducts students into a community of practice that itself is involved in defining the nature of good practice. The student cannot know the nature of good education prior to engaging in the educational process, and even then the nature of the good will remain in question. One answer to our question would be to say that online education contributes to a 
culture of individualised and consumerist learning that suppresses the examination of the purposes of education: online learning reinforces the impression that students are able to select a good product determined in advance. I believe there is some credibility to this analysis, but would not want to leave it there since it does not treat the nature of technology and being online in sufficiently ambivalent terms and might lead us to a romantic and unrealistic rejection of our technological being. In other words, there needs to be a way in which online education can express and shape reflection on the purposes of education in a substantive and meaningful way, without polarising the virtual and the physical.

I now turn to the philosopher Bernard Stiegler who understands digital technology and modern media as pharmacological: both poison and cure. Stiegler rejects the assumption that the human could exist prior to the technical, arguing that the evolution of human reflective awareness was concurrent with what he calls 'technics'. Indeed for Stiegler there is no human being without technics (Stiegler 1998, p. 134). Despite this, he is critical of the impact of modern technology and media on education and the youth in particular (Stiegler 2010). Yet Stiegler's analysis is interestingly ambivalent, coming out of a reading of critical theories of technology (especially Heidegger), but radically departing from them by his view that technics is coeval with hominization. I will develop an account of Stiegler's thinking on memory and attention.

\section{The Role of Tertiary Memory in Education}

Memory is the foundation of culture. The ancient Greeks mythologised this insight with the story of the goddess Mnemosyne, daughter of Gaia and Uranus, and mother, through union with Zeus, of the nine muses. Through Mnemosyne (memory), poetry, and the arts more generally, are made present. Without memory, then, culture could not exist. For Stiegler, the shared mnemonic heritage that is culture is passed on through a process of "exteriorisation" (Stiegler 2010, p. 127). Exteriorisations rely upon forms of prosthesis which might take prehistoric forms such as flint tools and wax tablets, or can appear in the more modern guises of books, magazines or forms of digital media and databases. Such prostheses are forms of tertiary memory, since they are distinct from the primary and secondary forms, namely, genetic inheritance and individual awareness.

In tertiary memory, then, experience can be liberated from genetic determinism or individual loss enabling humanity to pass on cultural inheritance. In prehistoric times cultural transmission would have been slow and fitful. Particularly from the 18th and 19th centuries this transmission is driven and appropriated by a more industrious and methodical spirit. Stiegler shows how the scientific revolution and the Enlightenment, with the perception of science as fundamentally progressive, inspired a new sense of the significance of history and the passage of time. ${ }^{6}$ The realisation of culture through memory is only possible through the development of technology as the material supports of tertiary memory. ${ }^{7}$ The technics that support tertiary memory constitute an awareness of time that

\footnotetext{
${ }^{6}$ Stiegler refers, for example, to the republic of letters of the 18th century in which the formation of a transnational and self-conscious metaphysical republic was possible through the ability to share information through the emergence of international networks (Stiegler 2010, p. 105ff).

7 Vlieghe (2014) emphasizes that for Stiegler it is not the case that these tertiary retentions aid our 'true memory' - there is no 'naturalised' organic memory that should be regarded as normative. Rather tertiary retentions are themselves memory. This is important because what we call memory is not, in this case, a passive faculty, but augments through contact with devices. In other words what we might call 'internal' memory is likely to change in relation to the kinds of exteriorization involved. As Vlieghe puts it "the
} 
entails the possibility of retention (looking backwards) and protension (looking forwards). In other words, the stitching together of temporality (of past and future) and the emergence of technics are one and the same event. It is here that we see technics as a key aspect of hominization. For Stiegler, the history of philosophy has suppressed the recognition of role of technics in the process hominization.

\section{The Pharmakon of Technics}

History, as the story of culture, is generally defined by its constitution through one particular technology: writing. Where written accounts exist we have entered 'history'. But this birth of history is marked by ambiguity, an undecidable that Derrida calls the pharmakon of writing (Derrida 1981). For Derrida the dual (and undecidable) nature of the pharmakon undercuts the binary logic that structures Western thought: it is not a matter of deciding whether writing reveals or conceals because it does both simultaneously. But doesn't this binary logic structure contemporary discussions about whether technology is an educational force good or a bad influence on the youth? We might want to avoid talking about 'technology' in a general and abstracted sense, a sense that is sometimes called 'essentialist', by arguing that each technical device has some educational potential and some dangers. ${ }^{8}$ For Derrida, though, this response would point to complexity but not 'undecidability' —an intrinsic and irreducible quality of ambiguity (Derrida 1994). Furthermore, I would argue that technologies have something undecidable about them: technology is both what puts power in our hands while simultaneously threatening to erode that power by making us blind to the scope and significance of own actions. As Günther Anders, speaking of atomic energy put it,

As engineers, at least as engineers of nuclear weapons, we have become omnipotent-an expression that is little more than a metaphor. But as intellectual beings we do not measure up to this omnipotence of ours...by way of our technology...we can no longer conceive what we can produce and do (Anders in Nordmann 2005).

Technology both makes us smarter and more stupid; engaged and disengaged, more potent and more powerless. Online environments feel much the same: they simultaneously present the world and hide it. Drawing on Heidegger's critique of technology, Albert Borgmann makes the point that the characteristic feature of technology—which he says is its ability to make things available to us in unprecedented ways-involves an erosion of the significance of things (Borgmann 1984). In other words, the more things are made available to us, the less significance things have for us. The more film and music become

Footnote 7 continued

human condition is above all a prosthetic condition" (Vlieghe 2014). In a post-Cartesian world we tend to assume that really the phenomena of our awareness, including memory, are internal to the physical brain, just as consciousness can only exist 'within'. I appreciate this emphasis because it resonates with the ancient (certainly pre-Cartesian) worldviews prior to the mind/body dualism, as well as showing intelligence (as logos) to be all around us as the inherent order of things. Of course this conception of logos is all too easily identified with a 'natural' (non-technical) order which I would want to question.

8 Andrew Feenberg has been critical of a tendency within 'classical philosophy of technology' especially that of Heidegger, to essentialise technology, which Feenberg calls 'substantivism' (Feenberg 1999, chapter 1). Iain Thomson has helpfully responded to Feenberg's critique showing that Heidegger is not a substantivist in the sense that Feenberg is concerned about (Thomson 2005, p. 47ff). Achterhuis has similarly encouraged the debate to take more account of the empirical detail of particular technologies rather than speaking of 'technology' (Achterhuis 2001). 
'on demand' the less committed my listening and viewing becomes. We see with MOOC's (massive open online courses) for example, that the extraordinarily enthusiastic take up does not translate in quite as extraordinary completion rates. ${ }^{9}$ Borgmann defines technological availability as what is rendered "instantaneous, ubiquitous, safe, and easy" (Borgmann 1984, p. 41). There are problems with this definition: for example, the digital divide between those who do and those do not have access to digital devices raises questions about ubiquity; the use of technology in violent or abusive acts, or issues of online privacy make 'safety' a questionable feature of availability. Despite these problems the definition does provide some insight into the way in which the world is made more available in the digital age. This definition of technical availability might well be applied to online environments and extended to online learning specifically (at least where they work well). But does this educational availability carry with it an uncanny disengagement with the substance of learning, as Borgmann might suggest? This is a question that we need to at least be able to ask. Do we not often mistake the content or process of education for education itself? In a similar sense, doesn't online education presuppose an educational model as little more than the transmission of knowledge, Freire's banking model? That is to say, does online education refer primarily to a bank of information that stands ready to be accessed, analogous to Heidegger's standing reserve (Heidegger 1977)? Does this explain why many online courses do not get much further than storing materials online accompanied by forum discussions? Is online learning not fundamentally reductive? Isn't education irreducibly rooted in the contact and relation between teacher and student a relation that cannot fully exist in an online world? The temptation to reinstate the binary at this point is to be resisted. A binary that takes online education to be existentially disconnected in contrast to an educational norm as entailing an unmediated presence of the other, rests upon the presumption of a pre-technical human that has never existed. Nevertheless, there is something to the concern that Borgmann raises: that there is both an uncanny disengagement in online environments, but equally a profound possibility.

Do we really need to argue for such technological ambivalence? I suggest that common sense finds the pharmakon of technology rather unthinkable. Populist views of science and technology tend to encourage binary judgements about the place technology. Science fiction often explores dystopian visions which encourage us to disregard the dual nature of the pharmakon. Even discussions within philosophy of technology have generally been characterised by exactly the kind of binary logic that the pharmakon seeks to undercut: Ellul, Heidegger and Marcuse and are often interpreted as straight-forward techno-pessimists, a view which does not stand careful scrutiny (Lewin 2011a). Conversely I could point to a raft of techno-optimists from Ray Kurzweil to Teilhard de Chardin, for whom more technology is key to our future (Lewin 2011b). As I have suggested, online learning is often viewed in similarly binary terms, as either eroding some aura of presence essential to the community of education, or as some panacea for our complex and overloaded lives. Many higher education institutions like the Open University, Stanford, or MIT embrace the opportunities of virtual learning though largely without asking seriously about the existential disengagement implied in online learning.

It would be convenient to reject technology as King Thamus rejected the offer of writing in order to remain in a natural state of immediacy with nature where our faculties

\footnotetext{
${ }^{9}$ Having said that, a $7 \%$ completion rate is still very impressive given the extraordinary sign up. Chris Parr, "Mooc completion rates 'below 7\%", Times Higher Education (May 2013) http://www. timeshighereducation.co.uk/news/mooc-completion-rates-below-7/2003710.article.
} 
can be employed in a fully human way. ${ }^{10}$ Even if we wanted to make such a rejection, we could not do so if technology is part of who we are. As Stiegler argues, the history of technogenesis is the history of anthropogenesis (Stiegler 1998). From this point of view, the problem of how to 'humanise' online learning might seem predicated on a false dichotomy that locates online as basically inhuman; unreal; absent; disconnected; disengaged. But the recognition that technology is central to human identity does not mean we uncritically embrace all that we call technology as the affirmation of human creativity. Technology - as the invention of writing or the splitting of the atom-is the pharmakon.

\section{The Threat to Critical Consciousness}

In his recent work, Stiegler has shifted his emphasis from hominization through technics to the related question of attention (Stiegler 2010). There is a clear connection to memory here since for Stiegler the ways in which memories are retained through technical exteriorisation have an impact upon the kind of attention that characterises human being. In other words, the development of attention (which might itself be the essential component of our being-in-the-world) is related to the development of technologies. The rise of new media technologies and the changing ways in which learners engage in multiple streams of attention (for example, listening, reading, and texting simultaneously) are surely more than coincidental. How is attention being shaped by new media technologies? In some respects, Stiegler's analysis in Taking Care of the Youth and the Generations is a rather hackneyed, neo-Frankfurtian attack on the dangers of a manipulative culture industry determined to commodify, colonise, and corrode the attention of the youth. Stiegler sees new media technologies as increasingly effective at manipulating attention and so the emergence of the new science of attention economics is both inevitable and alarming (Stiegler 2010, p. 94). With the proliferation of each form of new media-newspapers, pulp paperbacks, movies, television, the Internet and social media-emerges new worries about the creation of the next generation of 'I-don't-give-a-damners' (Stiegler 2010, p. 165). In this vein, Stiegler draws on Katherine Hayles' analysis of our media-rich environment in which our capacity for deep attention, especially in the youth, is being eroded (Stiegler 2010, p. 19ff). Deep attention is here being replaced by what Hayles calls hyper attention. ${ }^{11}$ Departing from Hayles' more even-handed interpretation of this shift (Hayles 2007), Stiegler views this negatively. With the erosion of deep attention and the infantilisation of culture we have, argues Stiegler, eroded adulthood because the critical maturity that defines adulthood is stunted or even entirely arrested (Stiegler 2010, p. 21ff). Stiegler is also keen to acknowledge the insights from brain imaging which establish the shifting scene of the brain by exploring synaptogenesis (Stiegler 2010, pp. 18-19). This is alarming Stiegler since not only are we weakening our attentional capacity, but, through the consequent restructuring of the brain, we are also in danger of irretrievably losing our intellectual maturity. However, if the research on synaptogenesis is accurate, then the restructuring of

\footnotetext{
10 In Plato's Phaedrus, Socrates recounts the story of the Egyptian King Thamus who is skeptical of the offer of the invention of writing. Thamus is concerned that his people will actually lose the power of memory through the reliance on an external form.

11 Hayles defines hyper attention as "characterized by switching focus rapidly among different tasks, preferring multiple information streams, seeking a high level of stimulation, and having a low tolerance for boredom" (Hayles 2007, p. 187). Stiegler seems to be working against the drift of Hayles' thought here who is keen to think "creatively and innovatively about new educational strategies appropriate to the coming changes" (Hayles 2007, p. 187).
} 
the brain itself is not as irretrievable as Stiegler seems to suggest (Stiegler 2010, p. 54ff). Pointing to the contradictions at the centre of Stiegler's project here, Richard Iveson says,

Proclaiming himself thus a prophet of and from potentially the last generation of mature adults, Stiegler seeks to hastily recall us to rational critique before the new media has its way and irretrievably restructures the connections which constitute intelligence so as to render such constitution impossible (Iveson 2012).

For Stiegler the effect of new media is, in a nutshell, the destruction of that hard-won product of Kant's Aufklärung, critical consciousness, which defines essence of educated adulthood.

What is somewhat ironic in Stiegler's account of the erosion of our critical consciousness is that it acknowledges the pharmacological nature of technological development, but then appears to rely on a conventional, even banal, critique of modern technology and new media as the manipulation and erosion of attention and critical consciousness. Stiegler argues that new media technologies are bringing about the proletarianization of the consumer by short-circuiting the attentional capacities of the youth and turning them into passive, even captive audiences. Stiegler is calling for a resistance to this proletarianization through the creation of more active and engaged forms of technology that create long-circuited practices in which the act of 'consumption' is more of an active construction. $^{12}$ While the total availability of the technological age might seem to encourage a consumptive attitude, much about the availability of online life suggests the opportunity to develop long circuits as Vlieghe shows:

Video-sharing websites, online encyclopedia, wireless connectivity and GPS-locating systems, and so forth might facilitate collaborative, democratic and emancipatory, production processes which fundamentally transform the society we live in. But mostly, we merely use them in such a way that they become the means of our own subordination to the laws of a consumerist economy (Vlieghe 2014).

Although Vlieghe and Stiegler recognise that technologies give shape to our actions and possibilities, there lingers the sense in which technologies to be used either for good or ill. This view could be read as supportive of technological neutrality: that it is up to the user to determine the good of the device. This is reminiscent of the old truism that 'guns don't kill people, people kill people'. But the discipline of philosophy of technology began with and is sustained by the insight that technology is not neutral (Lewin 2011a). Moreover the idea of technological neutrality does not seem to capture the intrinsic undecidability of the pharmakon. Indeed this is the point of Vlieghe and Stiegler's conception of technics: that technologies are not simply determined by the will of the user. This is my point with respect to the pharmacological nature of technology, that it is intrinsically undecidable. The common sense view of technological neutrality finds its way also into our conception of attention itself which can be conceived as a neutral faculty.

Common among psychologists is the view that attention is akin to a spotlight that the subject can point towards objects. This view of attention suggests that the spotlight itself does not alter what it points towards but only illuminates it-it is simply a faculty or tool. There are many problems with this view of attention as a neutral tool. For one, it disregards the historical constitution of attention, as if attention exists as an Archimedean point and that when we attend, we can see the world afresh. To see attention without regard to the

12 This is reminiscent of Borgmann's call for the development of "focal things and practices" (Borgmann 1984). 
social and historical conditions for its formation seems to invite a form of naïve realism (Lewin 2014). It also tends to ignore how attention is related to and affected by its object. If we consider with Stiegler that attention is affected by its object (Stiegler 2010; Stiegler 2012), then the ways in which different media form and shape attention become significant. The question of online learning can then be seen in terms of the ways in which technologies form attention rather than supposing that attention is a fixed and natural faculty that is either enhanced or diminished by our ever-developing technological milieu. We do not, then, need to begin our debate with questions like 'how do we stop the Internet from destroying our attention span?' Susan Greenfield, professor of pharmacology at Oxford University has recently raised concerns (not dissimilar to Stiegler) about the dangers of the growth in online living for our changing intellectual and attentional capacities. She says: "Whilst of course it [Internet use] doesn't threaten the existence of the planet like climate change, I think the quality of our existence is threatened-and the kind of people we might be in the future" (Semple 2010). Greenfield here is expressing a fairly conventional concern about the erosion of deep attention that Hayles says is needed for complex problem solving and sustained understanding. In the educational world in particular, deep attention is regarded as normative while hyperattention, useful though it may be in certain commercial contexts from air traffic control to currency trading, is connected to the loss of some essential aspect of human identity. But Hayles argues that the two forms of attention can be brought together: "stimulation by media, if it is structured appropriately, can actually contribute to a synergic combination of hyperattention and deep attention, which could have interesting implications for pedagogy" (Stiegler 2010, p. 75). Stiegler on the other hand, is less sanguine about such a synergy regarding hyperattention as too easily manipulated, rendering it a passive even captive form. We should, argues Stiegler, develop media that are able to elicit deep attention, and that create long circuits of attention.

As we move from what Stiegler characterises as the 'republic of letters' to an age of 'numeric programming' (a contrast that evokes the binary logic that cannot abide the undecidability of the pharmakon), we must, I think, be extremely alert to the dangers that Stiegler and Borgmann draw attention to. We can be sympathetic to Stiegler's concerns about the threat to critical consciousness without seeing life online as heralding the total destruction of the literate world, the irreversible short-circuiting of attention, or even the proletarianization of the consumer. There is, of course, a strongly political dimension to Stiegler's concerns. Indeed the formation of attention is never isolated but only takes place in dialogue with the social, a process that Stiegler calls individuation (Stiegler 2012). This individuation can be seen in the formation of attention, but also in the formation of desire. However, Stiegler is concerned that modern media not only replace deep attention with hyper attention, but desire, which should shape and be shaped in dialogue with the community (at least in the sense of a deliberative democratic republic), is decomposed to constituent and individualised drives (Stiegler 2010, pp. 12-13). Those drives become the individual preferences of the consumer that in some conceptions or democracy, are a given and inviolable commitment to be mediated by a politics of representation. We can see here a connection with Biesta's analysis of the consumerist attitude to learning in which the individual preferences are also inviolable, representing the start and end of the examination of purposes in education. Thus the long circuits of desire which in Plato's Symposium Diotima describes in hugely influential terms as a dialectical ascent to beauty itself, are short-circuited by drives which are the given reflexes of the human animal which simply must be satisfied. For Stiegler the mere satisfaction of drives entails infantilization because those drives are given and do not encourage inquiry into their own nature. 


\section{Time and Space are Out of Joint}

Up to this point I have sought to undercut any one-sided view of technology that opposes it to a putative natural state either in support of or resistance to technological interventions into education. I now want to consider whether philosophers of religion might have something relevant to contribute. After all, the religious traditions have consistently addressed the question of the proper formation of desire and the training of attention through varied types of religious and monastic practices. If technology is distracting, corrosive, and proletarianising of desire and attention, can religious interventions provide alternative perspectives? Is there any sense in which being online entails an attenuation or effacement of attention? In other words, where am I when I am online?

When online, vast educational resources are available to me in a de-distanced availability. I have already suggested that Borgmann would understand this availability as the erosion of significance. But can we clarify the nature of the loss? If online education overcomes spatio-temporal situatedness, does it simultaneously undo some essential qualitative dimension of spatio-temporality? I now turn to some ideas from the philosophy of religion in order to examine the role of space and time in relation to attention.

Mircea Eliade distinguished between sacred and profane with particular reference to the nature of time and space (Eliade 1961). I appreciate Eliade's analysis since it is sufficiently sensitive to specific religious contexts without being exclusivist: his analysis of ritual applies to many forms of religious life, and he sought to articulate broadly universal patterns without denying the significance of their locality and specificity. For Eliade, the significance of human life can be found through the structuring and delineating of space and time. Eliade speaks of the manifestation of the sacred as a hierophany (Eliade 1963), an event in which space and time are consecrated by a transcendent interruption of the mundane. The paradigmatic rituals of religious traditions bring that transcendent moment to presence by participating in it such that the performance of rituals re-enact, for example, the formation of the world, or the blessing of a place. In other words, the performance of the ritual sanctifies space and time, binding us to certain times and places. From the Sabbath to the Mass, specific rituals allow for a vertical interruption of the profane. In Eliade's view, myths and rituals provide structure and orientation to the world that would inhibit and disrupt the total availability of life online. Such inhibition and disruption of the everyday patterns are where significance itself comes from since these interruptions are characterised by their 'otherness': they cannot be circumscribed within the projections of the subject. Indeed, it seems as though the rituals are designed to disrupt everyday patterns. Attending the cathedral at evensong, oriented to the alter hearing the choristers that, theoretically, could be streamed direct to your mobile phone at my own convenience, opens a space for contingency: a place of encounter and otherness that is difficult, if not impossible to achieve online. But contingency does not happen by chance, so to speak. It must be structured by the ritual encounter in which both space and time are saturated with significance. Some traditions speak of the auspicious nature or providential ordering of the events. By contrast, life online might make any such disruption or ordering appear absurd. The encounter of ritual is problematic online because online environments tend to be circumscribed by the determinations of the controlling subject (or the programme that runs on the device). This could have relevance to online education since it argues for the irreducible significance of the physical encounter. This encounter is significant because the subject must relinquish control. Despite Eliade's convincing account of religious life, and the related conceptions of auspicious or providential ordering of the world, I remain uneasy 
about the privileging of the physical encounter, as though providence and ritual only make sense in a concretely physical sense. Eliade's ideas have been helpfully reworked by Jonathan Z Smith whose approach seems to offer something of a mediation.

Smith takes up but also departs from Eliade where he says "Ritual is, first and foremost, a mode of paying attention. It is a process of marking interest... It is this characteristic, as well, that explains the role of place as a fundamental component of ritual: place directs attention" (Smith 1992, p. 103). In brief, Smith's innovation of Eliade is the priority he gives to attention as the key component of presence and significance. Attention is the core dimension of ritual insofar as it interrupts the subjective projections that inattentive everydayness allows to structure existence by habits of desire (that for Stiegler seem to be supplanted by rather mindless drives). For Eliade this interruptive attention entails the specificity of sanctified time and space, in which singular times and places are 'given' (whether from God, or tradition) and so are not easily translated into the virtual. For Smith, on the other hand, space is sanctified by virtue of the act of attention and could therefore take place only in the mind and conceivably online. This is conceivable because the real goal of the disruptive encounter with the other must be the attention to the other. The significance of being disrupted is to see again with attention so that the subjective projections are interrupted.

\section{Conclusion}

The path we have taken has sketched out some of the relations between technology, time, attention and life online. Smith's development of Eliade has given us a way of redirecting our attention from the physical to the attentional, thus avoiding a crude opposition between the physical and virtual. For Stiegler attention and temporality are fundamentally related since the formation of attention is coeval with tertiary retentions available to us through technological innovations and it is those tertiary retentions that constitute our temporal existence. Thus authentic temporality and life online are not, in principle, mutually exclusive, though Stiegler does explore the risks to our critical attention of modern digital media. Elsewhere Stiegler has been keen to show the 'virtual' to be simply a new form of an ongoing process of humanisation:

Rather than talking about 'virtual space' one would have to refer to a new, digital, retentional system: a system which affects institutions of space and time, and which is no more and no less virtual than any other form of tertiary retention equally involving space and time (Stiegler 2003)

In principle then, online life is not essentially different from other forms of life experienced through tertiary retention.

We also considered Biesta's concerns about the culture of learnification and asked whether online education would reinforce and extend the pervasive and corrosive language of learning. I argued that online education does reinforce some aspects of learnification, but suggested that it does not need to. That is why I paired a discussion of Biesta with an ambivalent reading of technology and modern media. It is within the disruptive draft of this ambivalence, that the questions of significance and purpose are more likely to have traction and could, therefore, resist learnification.

The times and places of face-to-face education can work to structure time and space in ways that are disruptive. Those who want to be educated should not assume that education 
can come to them, anytime, anyplace, anywhere. Like good parenting, the role of structuring space and time, of drawing lines and limits to when and where good education takes place, is an important part of the job of educational institutions. Similarly, a good teacher knows when to interrupt, when to draw attention to the student's projections and assumptions, and when to leave them be. It is also part of the role of the institution to offer the structure and support that is not infinitely flexible or adaptable to the whimsical preferences of the student-as-consumer. This is pharmacological insofar as it both structures and inhibits us, but it is also educational in itself: learning to work with and through the institutional limits and structures. The disruptive nature of specific times and places can enable attention that is significant. But, along with Smith and Stiegler, I suggest that it is not the specificity of the place or time that is the point. It is the power to disrupt: to bring about fresh attention. And if Biesta is right that modern educational theory neglects reflection on the purposes of education, then this disruptive moment and the subsequent attention it provokes, might offer a challenge to the view of education as conforming to the subjective will of the student as consumer.

Open Access This article is distributed under the terms of the Creative Commons Attribution 4.0 International License (http://creativecommons.org/licenses/by/4.0/), which permits unrestricted use, distribution, and reproduction in any medium, provided you give appropriate credit to the original author(s) and the source, provide a link to the Creative Commons license, and indicate if changes were made.

\section{References}

Achterhuis, H. (Ed.) 2001. American Philosophy of Technology: The Empirical Turn. Trans. Robert Crease, Indiana Series in the Philosophy of Technology. Bloomington: Indiana University Press.

Bayne, S. 2015. What's the matter with 'technology-enhanced learning'? Learning Media and Technology 40(1): 5-20.

Biesta, G. 2006. Beyond learning: Democratic education for a human future. London: Paradigm.

Biesta, G. 2010. Good education in an age of management: Ethics, politics, democracy. London: Paradigm. Borgmann, A. 1984. Technology and the character of contemporary life: A philosophical inquiry. Chicago: University of Chicago Press.

Derrida, J. 1981. Plato's Pharmacy, Dissemination. Trans. B. Johnson. London: The Athlone Press, pp. 61-172.

Derrida, J. 1994. Spectres of Marx: The State of the Debt, the Work of Mourning and the New International. Trans. Kamuf. New York: Routledge.

Eliade, M. 1961. The sacred and the profane: The nature of religion. New York: Harper Torchbooks.

Eliade, M. 1963. Myth and Reality. Trans. Willard R. Trask. New York: Harper \& Row.

Feenberg, A. 1999. Questioning technology. London: Routledge.

Friesen, N. 2013. Educational technology and the 'new Language of Learning': lineage and limitations. In The politics of education and technology: Conflicts, controversies and connections, ed. N. Selwyn, and K. Facer, 21-38. London: Palgrave.

Friesen, N. 2014. Old literacies and the "New" literacy studies: Revisiting reading and writing. International Journal of Media Technology and Lifelong Learning 10(2): 73-88.

Hayles, K. 2007. Hyper and deep attention: The generational divide in cognitive modes. Profession 13: 187-199.

Heidegger, M. 1977. The Question Concerning Technology and Other Essays. Trans. W. Lovitt. New York, NY: Harper and Row.

Jacobs, A. 2015. 79 Theses on technology. For disputation. http://iasc-culture.org/THR/channels/Infernal_ Machine/2015/03/79-theses-on-technology-for-disputation/. Accessed 29 April 2015.

Iveson, R. 2012. Rewiring the brain, or, why our children are not human. Parallax 18(4): 121-125.

Lewin, D. 2011a. Technology and the philosophy of religion. Newcastle upon Tyne: Cambridge Scholars Publishing.

Lewin, D. 2011b. Technology and the good life: Suggestions for a theological turn in the philosophy of technology. Techné 15(2): 82-95. 
Lewin, D. 2013. 'Technology' in the oxford handbook of theology and modern european thought, 435-454. Oxford: Oxford University Press.

Lewin, D. 2014. Behold: Silence and attention in education. Journal of Philosophy of Education 48(3): 355-369.

Manifesto for teaching online 2011. Written by teachers and researchers in online education. University of Edinburgh MSc in E-learning. https://onlineteachingmanifesto.wordpress.com. Accessed 29 April 2015.

Masschelein, J. 2011. Experimentum Scholae: The world once more...But not (yet) finished. Studies in Philosophy and Education 30(5): 529-535.

Nordmann, A. 2005. Noumenal technology: Reflections on the incredible tininess of nano. Techné Research in Philosophy and Technology 8(3): 3-23.

Payton, R. 1991. The Ulu Burun writing-board set. Anatolian Studies 41: 99-106.

Semple, I. 2010. Oxford scientist calls for research on technology 'mind change' The Guardian. http://www. theguardian.com/science/2010/sep/14/oxford-scientist-brain-change. Accessed 29 April 2015.

Smith, J. 1992. To take place: Toward theory in ritual. Chicago: University of Chicago Press.

Stiegler, B. 1998. Technics and time I: The fault of epimetheus. Stanford: Stanford University Press.

Stiegler, B. 2003. 'Our ailing educational institutions' Culture Machine Vol 5. http://www.culturemachine. net/index.php/cm/article/viewarticle/258/243. Accessed 29 April 2015.

Stiegler, B. 2010. Taking care of the youth and the generations. Redwood, CA: Stanford University Press.

Stiegler, B. 2012. Relational ecology and the digital pharmakon. Culture Machine 13: 1-19.

Thomson, I. 2005. Heidegger on ontotheology: Technology and the politics of education. Cambridge: Cambridge University Press.

Vlieghe, J. 2014. Education in an age of digital technologies Flusser, Stiegler, and Agamben on the idea of the posthistorical. Philosophy and Technology 27(4): 519-537.

Wegerif, R. 2007. Dialogue, education and technology: Expanding the space of learning. New York: Springer. 